\title{
Status of Internet use for Higher Education and Research in Agricultural Sciences
}

\author{
M. A. Zaman ${ }^{1 *}$ and S. M. Iqbal Hossain ${ }^{2}$ \\ ${ }^{1}$ Dept. of Farm Power \& Machinery, Bangladesh Agricultural University, Mymensingh, Bangladesh \\ ${ }^{2}$ Dept. of Agricultural Engineering, Bangabandhu Sheikh Mujibur Rahman Agricultural University, \\ Gazipur-1706, Bangladesh
}

*Corresponding author and Email: zamanma_bd@yahoo.com

Received: 04 January 2012

Accepted: 26 May 2012

\begin{abstract}
A study was conducted to explore the role of internet on higher education and research at two selected public universities in Bangladesh, which offer courses on Agricultural Sciences. One hundred and fifty eight teachers and 79 post-graduate students were interviewed based on questionnaires. It was found that $90.8 \%$ teachers had internet connectivity and they used internet on regular basis to search relevant websites and download the selected course contents. All the teachers agreed that adequate and reliable information on different topics of Agricultural Sciences can be obtained through internet, which can be used for academic and research purposes. Use of internet by the students is being gradually increased in public universities. The universities are expanding the internet facilities to increase services to the teaching and learning communities. Digitization of libraries and internet links between the public universities libraries are in progress. It is expected that the use of internet would bring significant changes in higher education and research systems of developing nations and the institutions of higher education would attain a global standard. Development of education in these countries are badly influenced by limited resource and poor finance.
\end{abstract}

\section{Keywords: Higher education, agricultural sciences, internet for higher education}

\section{Introduction}

Higher education is crucial for the production of vital human resources for socio-economic development of a nation. Higher education is also important for political stability and peace, as well as building democratic culture and cohesive societies (Yizengaw, 2005). In today's world, a national issue, in one way or other, may influence global issues, for example, climate change and food security. Higher education, therefore, should have an aim to generate skilled manpower to tackle the present and future challenges of the world communities. On the dawn of a new millennium, the world is facing increasing globalization in different areas of human lives. An increasing migration of professionals from one country to another are being observed, and the rise of the 'global professional' qualified to provide services in any country of the world. This inevitably is giving way to an introduction of internationally accepted educational standards and requirements (Wojtczak and Schwarz, 2000).

Inclusive quality education is fundamental to achieving human, social and economic development. Governments as well as all the other social actors have an important role in providing quality education for all and, in doing so, should recognize the importance of a broadened concept of inclusive education that 
addresses the diverse needs of all learners and that is relevant, equitable and effective (UNESCO, 2008). Forty eighth sessions of the International Conference on Education (ICE) recommended to "Strengthen the use of ICTs in order to ensure greater access to learning opportunities, particularly in rural, remote and disadvantaged areas" and to "Provide high quality, informal educational opportunities that offer the possibilities for formal recognition of competencies acquired in non-formal settings". UNESCO is committed to "Encouraging efforts to increase resources for education both at national and international levels". In order to promote ICT-based teaching and learning, Regional and International cooperation is badly required for policy making and adequate financing (UNESCO, 2008).

Traditional systems of higher education in public universities of developing countries are based on printed books and journals. Most of the books on Agricultural Sciences are imported and students often cannot afford to purchase these books. Also, the university libraries in developing countries cannot have adequate stock of Text and Reference books due to financial constraints. Procurement and collection of books sometimes require long time. For these reasons book-based traditional system of teaching and learning is hampered. In addition, text books become outdated after publication and academic research suffers a lot due to unavailability of updated information. Recent developments on the internet technologies, development of world wide websites with a vast treasure of educational information, have drastically reduced the dependence on printed books and journals. Virtual libraries with digitized books and journals are now available online. These information can be easily accessed and downloaded through internet at any time from anywhere without any cost.

The internet as swiftly entered into the life of humankind in the 20th century, it has become not only the hugest information resource in the world but also the most rapid means of communication. People from different countries have got an opportunity to communicate with each other in a very short time. In comparison to a snail-mail or even airmail, e-mail gets over distance and time, and frontiers of the states with a lightning speed. Students can enhance their knowledge using the educational literature, encyclopedia, references, dictionaries, and databases, which are freely accessed; participating in distance educational courses, in collaborative projects with students from other schools and universities in other countries, and discussing different problems with them. So, the opportunities, which internet can offer in the sphere of education, are really unique (IITE, 2003). With the advent of information communication technology, more and more educators are exploiting the internet tools e.g. the World Wide Web (WWW) and e-mail in order to make their educational materials available and accessible online (Zabel, 1998). Probably, the education most influenced by information technology is that at the university level. The Internet, when used properly, can close the education gap between the developed and the developing nations. The internet has dramatically increased access to information. This study was, therefore, undertaken to explore the role of internet on higher education and research at two selected public universities in Bangladesh, which offer courses on Agricultural Sciences as well as conduct research.

\section{Methodology}

A study was conducted in 2010 to explore the role of internet on higher education and research at Bangladesh Agricultural University (BAU) and Bangabandhu Sheikh Mujibur Rahman Agricultural University (BSMRAU). Both the Universities offer courses on Agricultural Sciences. Teachers and post-graduate students were interviewed based on questionnaires. During this study there were 512 teachers in BAU, of whom 457 had internet connectivity. In BSMRAU all of 84 teachers had internet connectivity. One hundred and thirty (130) teachers and 58 post-graduate students from 
different disciplines of BAU and 28 teachers and 21 post-graduate students from different disciplines of BSMRAU were randomly selected for interviewing. A total of 158 teachers and 79 post-graduate students were thus sampled for this study.

Data were collected on the status of internet connectivity in selected universities; extent and type of internet use by the teachers and students; skills in internet use; comments on the availability, relevance, authenticity and quality of course contents found on the websites. The collected data were analyzed for different statistical parameters using Microsoft Excel.

\section{Results and Discussion}

\subsection{Status of internet connectivity in BAU}

ICT infrastructure has been developed to provide internet connectivity to teachers and student in BAU campus. The system was started functioning in July, 2008. The capacity of the infrastructure is above 3000 and by now about 450 users are being served. The internet connectivity is administered centrally through a hired Internet Service Provider (ISP). In BAU Library $20 \mathrm{PCs}$ connected to Internet are reserved for the students. The Department of Computer Science, under the Faculty of Agricultural Engineering \& Technology, recently installed $\mathrm{WiFi}$ wireless system to provide internet connectivity to the students, who are interested to use this facility outside the Department building within $100 \mathrm{~m}$ range. The students, who has laptop computer, can avail this free facility. Similar facilities will be developed soon in Residential Halls for the students. Use of the internet provides great educational benefits to students and faculty members. The Department of Computer Science has been offering ICT related education including a Postgraduate Diploma in Information and Communication Technology (PGD-in-ICT).

\subsection{Status of internet connectivity in BSMRAU}

Internet facilities have been developed in collaboration with Bangladesh
Telecommunications Company Limited (BTCL). All the departmental teachers and administrative officers have internet connectivity. Five access points have been made available for PG students in the library, which will be expanded as per demand.

\subsection{Use of internet resources}

The connection to internet is the first and crucial condition of internet use. Every teacher should own a computer with internet connectivity. Out of 596 of the two universities, 541 teachers (90.8\%) had personal computer with internet connectivity.

About $75 \%$ of the PG students own computers. The students are now using internet facilities provided by the BAU library and the Department of Computer Science. Private ISPs are also available in BAU Campus. The students have to pay for internet browsing from private ISPs. BAU authority is planning to provide free IT services to the students in near future.

\subsection{Type of internet use}

Both the teachers and students are aware of the internet facilities such as e-mail, chatting, browsing for information and internet phoning. However, most of the teachers were found to use e-mail communication (100\%), browsing for teaching materials $(98.1 \%)$ and research materials $(97.5 \%)$ as shown in Table 1. Newly recruited teachers browse for scholarships (41.88\%) also. Teachers spend 3-7 days per week and 1-8 hours per day for internet browsing.

The students use internet for browsing and downloading class materials and materials for assignments, e-mail, chatting, reading newspapers and listening to music. The graduate students search internet for course and research materials and for e-mail communication (100\%), for jobs $(58.2 \%)$, and for scholarship (68.4\%) as shown in Table 2. The PG students spend 1-2 hours per day for internet. 
Table 1. Type of internet use by teachers

\begin{tabular}{lcc}
\hline Type of use & Respondents (No.) & Respondents (\% of total) \\
\hline e-mail communication & 158 & 100 \\
Chatting & 42 & 26.6 \\
Browsing for scholarship & 66 & 41.8 \\
Browsing for better job & 14 & 8.9 \\
For course materials \& assignments & 155 & 98.1 \\
For research materials \& publications & 154 & 97.5 \\
For materials of personal interest & 97 & 61.4 \\
Recreational (news, music, travel, etc.) & 136 & 86.1 \\
\hline
\end{tabular}

Total number of respondents (teachers), $n=158$

Table 2. Type of internet use by PG students

\begin{tabular}{lcc}
\hline Type of use & Respondents (No.) & Respondents (\% of total) \\
\hline e-mail communication & 79 & 100 \\
Chatting & 47 & 59.5 \\
Browsing for scholarship & 54 & 68.4 \\
Browsing for job & 46 & 58.2 \\
For course materials \& assignments & 79 & 100 \\
For research materials \& publications & 79 & 100 \\
For materials of personal interest & 75 & 94.9 \\
Recreational (news, music, travel, etc.) & 48 & 60.7 \\
All & 31 & 39.2 \\
\hline
\end{tabular}

Total number of respondents (PG students), $\mathrm{n}=79$

\subsection{Skills for internet use}

Using internet requires sufficient skill, which can be obtained through regular practice. Some of the senior teachers have not yet mastered in internet browsing and some are not interested either. About $85 \%$ of the students reported that they have learnt using internet and browsing for information from their friends (Table 3). Regular and long-time users have gathered adequate skill in using internet and downloading information from the webs. The students in general face problem of information management. Finding and selecting appropriate information by browsing websites is really difficult for them. They also find it difficult to arrange the collected information chronologically. They need proper guidance in this regard from respective teachers.
A more important task is to make sure that the students can process the information and transform it to knowledge with relevant contexts.

\subsection{Relevance, authenticity and quality of course contents}

While the use of internet has grown, there is a growing concern that the users are getting the right information. The students were asked about the availability, relevance, authenticity and quality of the course contents downloaded from the Internet. Their comments are presented in Tables 4 and 5. An overwhelming majority (93.7\%) agreed that the course contents are adequate; $86.1 \%$ said that the information derived from internet is relevant to their courses and $82.2 \%$ said that the course contents are authentic. 
Table 3. From whom the students learnt browsing technique $(n=79)$

\begin{tabular}{lcc}
\hline From whom learnt browsing & Respondents (No.) & Respondents (\% of total) \\
\hline Teachers & 6 & 7.6 \\
Internet Service Provider & 3 & 3.8 \\
Friends & 67 & 84.8 \\
Family members & 3 & 3.8 \\
\hline
\end{tabular}

Table 4. Students comments on the availability of course materials from Internet $(n=79)$

\begin{tabular}{lcc}
\hline Comment & Respondents (No.) & Respondents (\% of total) \\
\hline Adequate/ More than adequate & 74 & 93.7 \\
Inadequate & 5 & 6.3 \\
\hline
\end{tabular}

Table 5. Students comments on the relevance, authenticity and quality of course materials obtained from Internet $(\mathrm{n}=79)$

\begin{tabular}{|c|c|c|}
\hline Comment & Respondents (No.) & Respondents (\% of total) \\
\hline \multicolumn{3}{|l|}{ Relevance and quality } \\
\hline Excellent/Good & 68 & 86.1 \\
\hline Fair & 11 & 13.9 \\
\hline Updated Information (yes) & 75 & 94.9 \\
\hline Authentic Information (yes) & 65 & 82.2 \\
\hline Presence of visual display (yes) & 46 & 58.2 \\
\hline
\end{tabular}

Table 6. Teachers comments on the relevance, authenticity and quality of course materials obtained from Internet $(\mathrm{n}=158)$

\begin{tabular}{lcc}
\hline Comment & Respondents (No.) & Respondents (\% of total) \\
\hline Relevance and quality & & \\
Good/Excellent & 155 & 98.1 \\
Updated Information (yes) & 158 & 100 \\
Authentic Information (yes) & 146 & 92.4 \\
Presence of visual display (yes) & 153 & 96.8 \\
\hline
\end{tabular}

All the teachers agreed that the course contents available from relevant websites are adequate and the information are regularly updated. Regarding the relevance to the syllabus and the quality of the available materials, $98.1 \%$ respondents agreed that the materials are either good or excellent and $92.4 \%$ said that the information derived from internet is authentic with the citations of references (Table 6).

Experienced users can easily detect the faults in the information collected from the internet. In case of ignorance, one can download information from several locations and compare them for 
relevance, quality and completeness. There are websites which are already famous for hosting quality and reliable information. Information provided in the internet by recognized Govt. and international organizations are also reliable. For reliability the following criteria may be followed (Brdicka, 2003): author, organization, reason of publishing (conference, special event, etc.), year of publishing. Some other things to be considered are: level of use of foreign language, extensive use of technical terms in the material, relevance for the topic, etc. Sites that provide a remunerative service are recommended because the accuracy and reliability of the information are practically guaranteed.

\subsection{Promotion of ICT in higher education}

The majority of senior faculty members had no access to internet when they were students. Books and libraries were practically the only source of information available for their research. This situation poses hindrance in adapting ICT tools by the senior teachers. The faculty members must be conscious of the needs of this new generation and accept that some changes must be made in the way they teach. For professional interest and for greater interest of the present day students, they must know how to use ICT tools and apply these in teaching and learning process. The present study reveals that the teachers perform a minimum responsibility of giving assignment that involves the students to browse internet $(73.4 \%$ ); only $5.7 \%$ teachers teaches how to browse internet (Table 7). Professors should encourage students to combine the use of the internet and libraries for their research works.

\subsection{Websites for resource information}

Key word searches using Google Search were conducted to explore the course contents of Agricultural Sciences. Amazingly enormous information on each and every topic was found available on the internet. Google Search is enough to find other useful resource websites containing vast information on Agricultural Sciences.
The use of the World Wide Web appears to offer a number of unique benefits to education such as increasing accessibility and student motivation. Web-based learning can supplement or replace traditional education system. The internet's great strength is that it can make instruction timeindependent and location-independent. Multimedia projects can improve educational outcomes by enabling students to represent information using different media, to link and organize information in many meaningful ways; to draw knowledge and experiences from a wide range of sources; to practice problem-solving and decision-making; to achieve high self-esteem and to become more self-directed.

Special websites, called search engines are available on the internet to search information on almost every topic. The search engines like Google and Yahoo are famous worldwide. Other popular search engines are altavista.com, search.com, ask.com, etc. The scientists, writers, engineers and many other professionals use these search engines to collect latest information for different purposes. Students, academicians and researchers are among the top users who use the internet for education and research. Vast reserves of news, advertisement, and information on entertainment, matrimony and travel guides are available on the internet. Online education, medical advice and expert services are also available. Social networking sites like Facebook are popular among the students. They may also use some messaging services of the internet, for example Yahoo Messenger, Windows Live Mail messenger, Gmail etc. which allow chatting between students.

Many websites are dedicated to teachers. Teachers can now search the web for lesson plans and teaching best practices as well as research. The interconnection of networks provides easy access to information around the globe. Databases of information are linked over vast geographical differences, creating a library of information that can be accessed anytime from anywhere. Years of statistical information, experimental studies, published research and 
Table 7. How teachers encourage students for browsing internet. $(\mathrm{n}=158)$

\begin{tabular}{lcc}
\hline & Respondents (No.) & Respondents (\% of total) \\
\hline (i) Ask for browsing only & 25 & 15.8 \\
(ii) Ask for browsing \& give assignment & 116 & 73.4 \\
(iii) Teach how to browse & 9 & 5.7 \\
All (i, ii and iii) & 8 & 5.1 \\
\hline
\end{tabular}

compilations of various data are available at just a click of a mouse. Every teacher should also have a favorite and serious source of professional information. Everybody should be able to find the suitable directory for individual purposes in a short time. Some of the Resource Websites for search (Brdicka, 2003) are listed below.

- Google Directory (http://directory.google.com/)- The keyword and the full-text search engines are integrated.

- Yahoo World Directory (http://www.yahoo.com/)

- European Schoolnet (http://www.eun.org/) One of the prime sources of information for the teachers in Europe.

- Education World (http://www.educationworld.com/regional/)- education focused directory.

- Kathy Schrock's Guide for Educators (http://school.discovery.com/schrockguide/)Professional's directory.

- Copernic (http://www.copernic.com/)- locally installed programs.

- Portals - a combination of directories and search engines. Often include free E-mail accounts, discussion forums, chat, WWW publishing, virtual malls, etc.

- TeAch-nology (http://www.teachnology.com/)- The Best on the Web for Teachers service.

- AskERIC (http://ericir.syr.edu/)- A service financed by American Govt.

- EUN eSchoolnet (http://www.eschoolnet.org/)- owned by the British Educational Communications and Technology Agency (BECTA).

- Ferl (http://ferl.becta.org.uk/)

- Canadian Schoolnet (http://www.schoolnet.ca/home/e/resources)
- Ask an Expert service (http://www.classroom.com/community/expert $\mathrm{s} /$ )- For methodological assistance.

- The Lesson Plans Page (http://www.lessonplanspage.com/).

- Collaborative Lesson Archive (http://zubov.atmos.uiuc.edu/CLA/).

Some of the suitable resources for students are universal. These are the encyclopedias, databases, archives, museums, etc. In its possibilities the Internet offers much wider choice than even the largest collection of CDROMs. The directories with potentially useful links for students would probably be more sufficient. The following addresses are worth trying:

- http://www.kidskonnect.com/

- http://www.infoplease.com/

- http://www.mrdowling.com/

- http://www.biblio.usherb.ca/internet/encyclo.htm.

There are also specialized services dedicated directly to the students similar to those for teachers'. Students may need assistance when they cannot find what they are looking for. The English-speaking students can use various askreply services such as:

- Ask Jeeves - http://www.askjeeves.com/),

- Ask An Expert http://www.askanexpert.com/,

- All Experts http://www.allexperts.com/,

- Ask Dr. Math http://forum.swarthmore.edu/dr.math/,

- Ask-A-Scientist http://www.madsci.org/,

- Ask Dr. Universe http://www.wsu.edu/DrUniverse/).

There are even several servers specialized in assisting with doing the home assignments:

- http://www.schoolwork.org/ 
- http://school.discovery.com/homeworkhelp/bj pinchbeck/.

An exceptional source of materials is the archive of the international prestigious competition ThinkQuest (http://www.thinkquest.org/).

Online Encyclopedia's are available as the vast treasures of knowledge:

- Encyclopedia - Britannica Online Encyclopedia [http://www.britannica.com/]

- Wikipedia, the free encyclopedia [http://en.wikipedia.org/wiki/Internet]

- Banglapedia - Wikipedia, the free encyclopedia [http://www.bpedia.org/]

\section{Conclusions}

Tremendous development has taken place in the field of ICT sector during the last 10 yeas in Bangladesh. It has brought a great change in the process of teaching and learning in higher education. It is evident from the aforesaid discussion that about 90.8 per cent teachers had personal computer with internet connectivity while almost all teachers use e-mail communication and browse internet for teaching materials and research materials. Besides, all the graduate students $(100 \%)$ search internet for course and research materials, and e-mail communication while about $68 \%$ students browse for scholarship and $58 \%$ for jobs. However, majority of the students $(85 \%)$ do not have any formal training on internet use; they learned internet browsing for information from their friends.

The current stage of development demands every classroom to be equipped with a computer and a set of multimedia presentation facilities. The university library should be digitized and linked with other libraries of the country. The universities should, therefore, strengthen the use ICT tools to facilitate both teachers and students with internet hardware, software and training for substantial development of higher education in the country.

\section{References}

Brdicka, B. 2003. The Role of Internet in Education. (C) BoBr 2003. [Available at http://it.pedf.cuni.cz/ bobr/role/econt.htm]. Retrieved on 20.6.2010.

IITE. 2003. Internet In Education. Support Materials for Educators. IITE Training Materials. UNESCO Institute for Information Technologies in Education (IITE), Moscow, 2003.

UNESCO. 2008. "Inclusive Education: The Way of The Future". International Conference On Education. United Nations Educational, Scientific and Cultural Organization Forty eighth session. International Conference Centre, Geneva, 2528. 28 November 2008.

Wojtczak, A. and Schwarz, M. R. 2000. Minimum essential requirements and standards in medical education. Medical Teacher, vol. 22 no. 6 .

Yizengaw, T. 2005. Policy development in higher education in Ethiopia and the role of donors and development partners. Paper presented at the International Expert Meeting- Formulas that work: Making Higher Education Support More effective; The Hague, The Netherlands, 23-24 May 2005.

Zabel, D. 1998. Integrating the Internet into the hospitality curriculum: more than a listing of 'cool' websites. Journal of Hospitality \& Tourism Education, 9: 66-73. 